Supporting Information

\title{
Facile Construction of Copper-containing Covalent Bond for Peroxymonosulfate Activation: Efficient Redox Behavior of Copper Species via Electron Transfer Regulation
}

Ting Chen, ${ }^{\text {add }}$ Zhiliang Zhu, ${ }^{* a, b, d}$ Hua Zhang, ${ }^{a}$ Yanling Qiu, ${ }^{\text {b,d }}$ Daqiang Yin, ${ }^{\text {b,d }}$ and Guohua Zhao*c

${ }^{a}$ State Key Laboratory of Pollution Control and Resource Reuse, Tongji University, Shanghai 200092, China

${ }^{b}$ Key Laboratory of Yangtze River Water Environment, Ministry of Education, Tongji University, Shanghai 200092, China

${ }^{c}$ School of Chemical Science and Engineering, Tongji University, Shanghai 20092, China

${ }^{d}$ Shanghai Institute of Pollution Control and Ecological Safety, Shanghai 200092, China

Corresponding author: Zhiliang Zhu \& Guohua Zhao

*Zhiliang Zhu, Professor

State Key Laboratory of Pollution Control and Resource Reuse, 
Tongii University, 1239 Siping Road, Shanghai 200092, China.

E-mail: zzl@tongji.edu.cn

*Guohua Zhao, Professor

School of Chemical Science and Engineering,

Tongji University, 1239 Siping Road, Shanghai 200092, China.

E-mail: g.zhao@tongji.edu.cn

The supporting information included: 13 pages, 2 texts, 1 table and 14 figures. 


\section{Text S1 Characterization of catalysts}

The surface morphology and structure of the catalysts were characterized by scanning electron microscope (SEM, Nova nanoSEM 450, FEI, Netherlands) and high resolution transmission electron microscopy (HRTEM, FEI, TF20/2100F). N2 adsorption-desorption isotherms and pore size distribution were measured using an Autosorb-iQ analyzer (QuantaChrome, USA). XRD pat-terns were recorded on a D-8 Advance X-ray diffractometer (Bruker-AXS, Germany) with $\mathrm{Cu} \mathrm{K} \alpha$ radiation operating at $40 \mathrm{kV}$ and 40 $\mathrm{mA}$ in the $2 \theta$ range of $10^{\circ}-70^{\circ}$. Raman spectra was scanned on a LabRAM HR Evolution (HORIBA, France) with a $532 \mathrm{~nm}$ laser light irradiation. Thermogravimetric analysisdifferential scanning calorimetry (TGA-DSC) was performed on a Q600 SDT thermal analyzer over the temperature range of $50-800{ }^{\circ} \mathrm{C}$ under a nitrogen atmosphere at a heating rate of $10{ }^{\circ} \mathrm{C} \mathrm{min}^{-1}$. Fourier transfer infrared (FTIR) spectrum was measured by Bruker Ten-sor37 (Bruker-AXS, Germany) FTIR instrument. The functional groups and related oxidation states on the surface of the samples were characterized on a X-ray photoelectron spectroscopy (XPS, Thermo Fisher ESCALAB 250Xi, USA). The measurement of $\mathrm{H}_{2}$ temperature programmed reduction $\left(\mathrm{H}_{2}-\mathrm{TPR}\right)$ was pre-treated at $400{ }^{\circ} \mathrm{C}$ for $2 \mathrm{~h}$ under pure argon flow then reduced by $5 \% \mathrm{H}_{2} / \mathrm{Ar}$ gas mixture from 50 to $800{ }^{\circ} \mathrm{C}$ at a rate of $10{ }^{\circ} \mathrm{C} / \mathrm{min}$. Electrochemical Impedance Spectroscopy (EIS) and Cyclic voltammetry (CV) measurement of each sample were measured by using three-electrode electrochemical cell equipped with a catalyst coating glass carbon as working electrode and a graphite carbon 
rod as counter electrode in a $0.1 \mathrm{M} \mathrm{Na}_{2} \mathrm{SO}_{4}$ solution with PMS of $0.5 \mathrm{mM}$ concentration at a scanning rate of $50 \mathrm{mV} / \mathrm{s}$. The saturated calomel electrode (SCE) was regarded as reference electrode. The ESR measurements were carried out on a Miniscope MS-5000 ESR spectrometer (Germany), using 5, 5-Dimethyl-1-pyrrolidine-N-oxide (DMPO) and 4Amino-2,2,6,6-tetramethylpiperidine (TEMP) as the spin-trapping agents for reactive species.

\section{Text S2 Analytical methods}

The concentrations of the mixture solutions were determined using a ultraperformance liquid chromatography (UPLC) with an UV-vis photodiode array detector and an ACQUITY UPC2 BEH C18 column: $100 \times 3.0 \mathrm{~mm}, 1.7-\mu \mathrm{m}$ particle size. The ultrapure water and acetonitrile were used as mobile phase with the water/acetonitrile of 75:25 for TAP, 55: 45 for CAP, 70: 30 for FF. The detective limit of the compounds in this UPLC was $50 \mathrm{ug} \cdot \mathrm{L}^{-1}$.

The reaction rate was evaluated by first order kinetics model using eq s1:

$\ln \left(C_{t} / C_{0}\right)=-k_{\text {app }} \mathrm{t}$

Where $C_{0}$ is the initial pollutant concentration, $C_{t}$ is the concentration at a certain time

$(t)$ during the degradation process, and $k_{a p p}$ is the reaction rate constant. 
The total organic carbon (TOC) was measured by a Shimadzu TOC-VCPH Analyzer. The released metallic ions in the reaction system were detected on a Agilent 720 (Agilent, USA) ICP-OES.

Table S1 ESR-measured g value for $\mathrm{Cu}^{2+}$ species in various samples

\begin{tabular}{|c|c|c|}
\hline Samples & $\mathbf{g}_{\|}$ & $\mathbf{g}_{\perp}$ \\
\hline $\mathrm{CuAl} @ \mathrm{CN}$ & 2.2783 & 2.0780 \\
\hline $\mathrm{CuAl} @ \mathrm{O}-\mathrm{CN}_{\mathrm{D}}$ & 2.3330 & 2.1411 \\
\hline
\end{tabular}

(a)

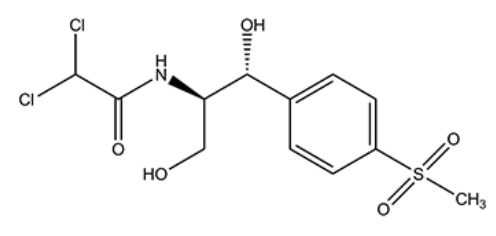

(b)

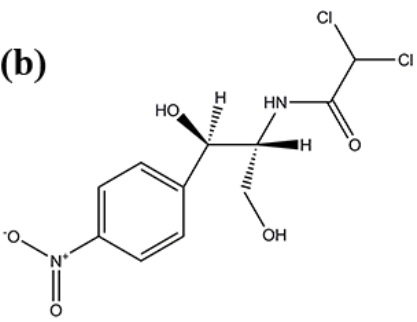

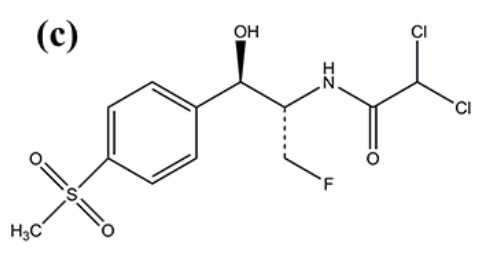

Figure S1 Structures of (a) thiamphenicol (TAP), (b) chloramphenicol (CAP), (c) florfenicol (FF). 


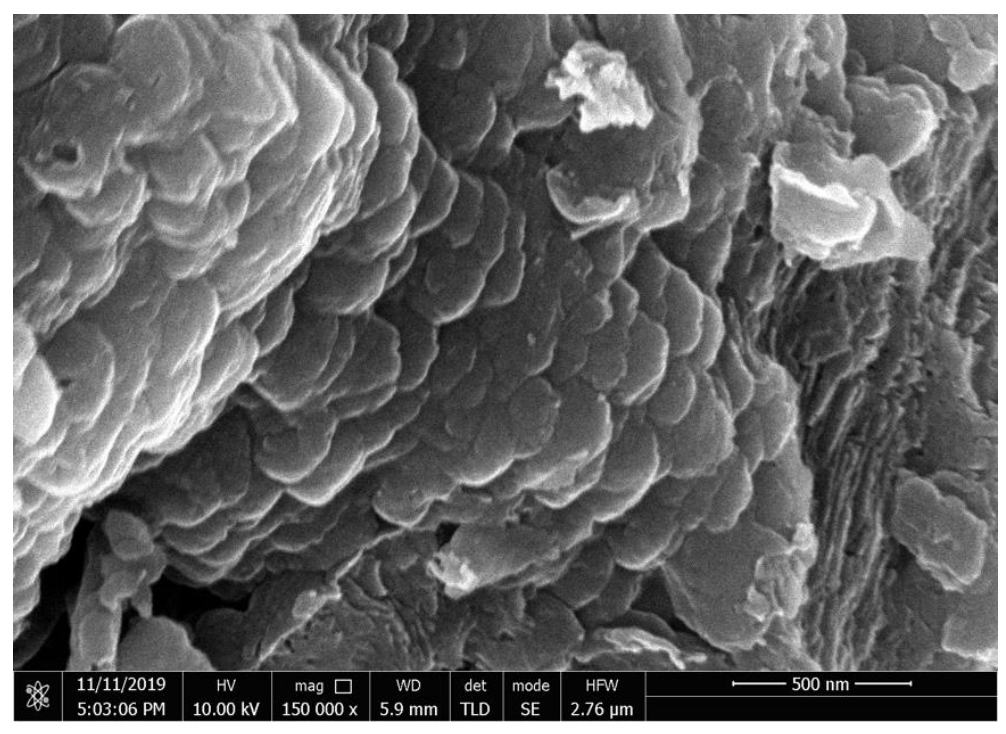

Figure S2 SEM image of $\mathrm{g}-\mathrm{C}_{3} \mathrm{~N}_{4}$.

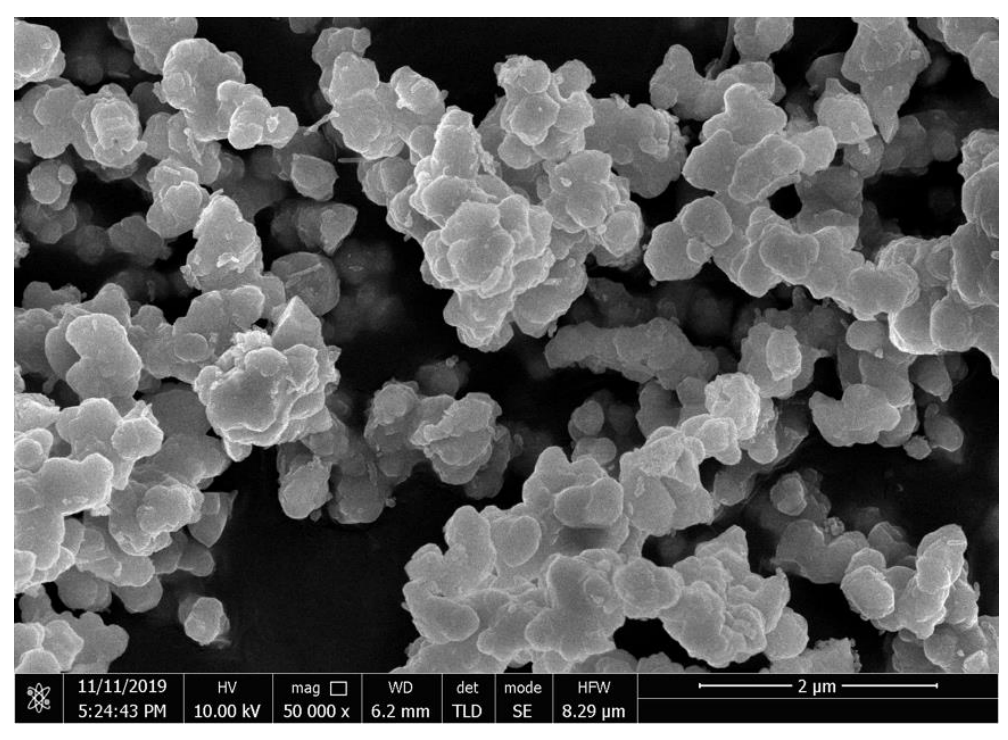

Figure S3 SEM image of $\mathrm{CuAl}_{x} \mathrm{O}_{y}$. 


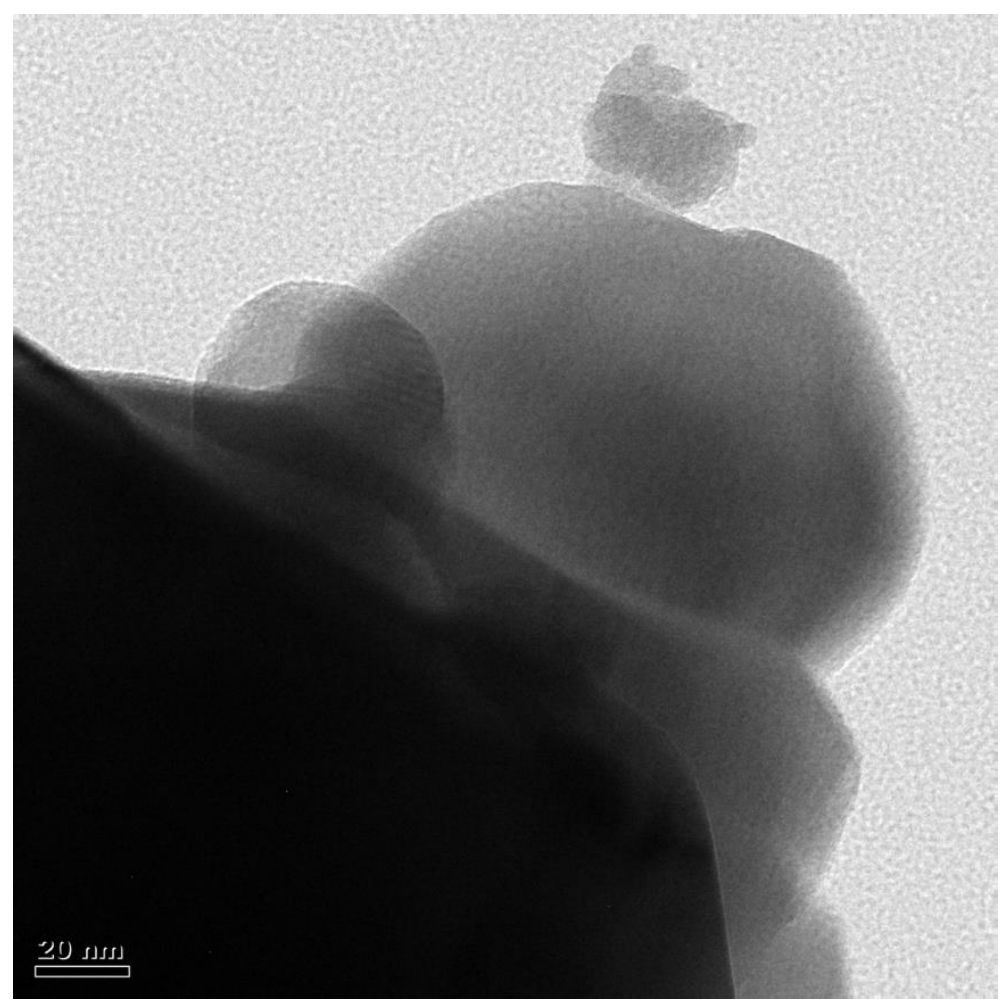

Figure S4 TEM image of $\mathrm{CuAl}_{x} \mathrm{O}_{y}$.

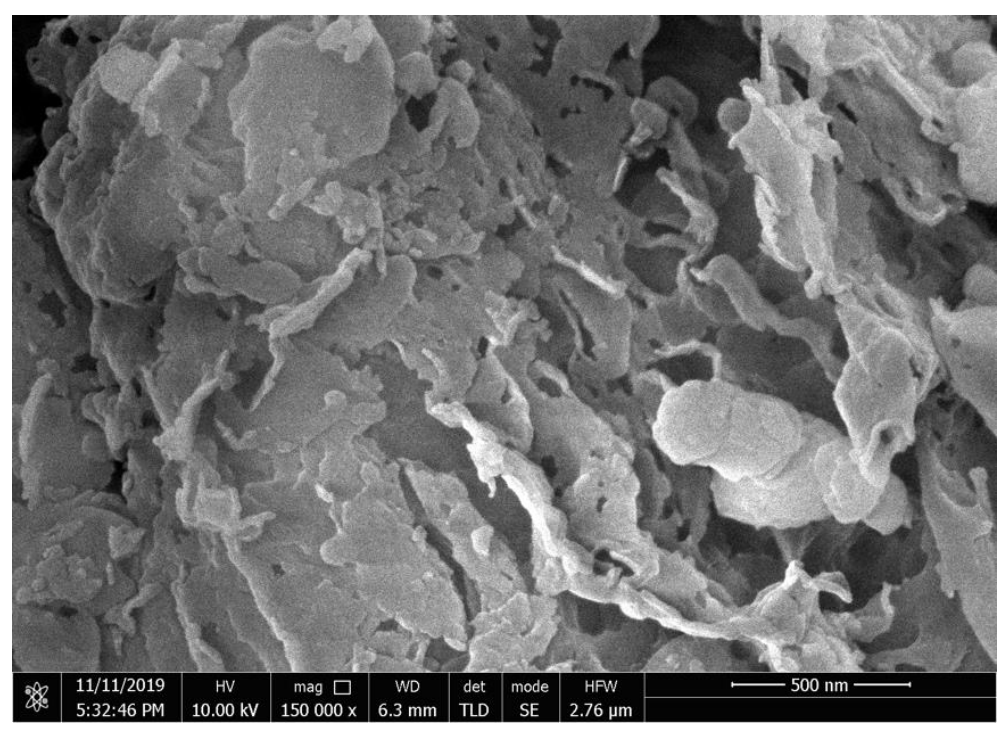

Figure S5 SEM image of CuAl@CN. 

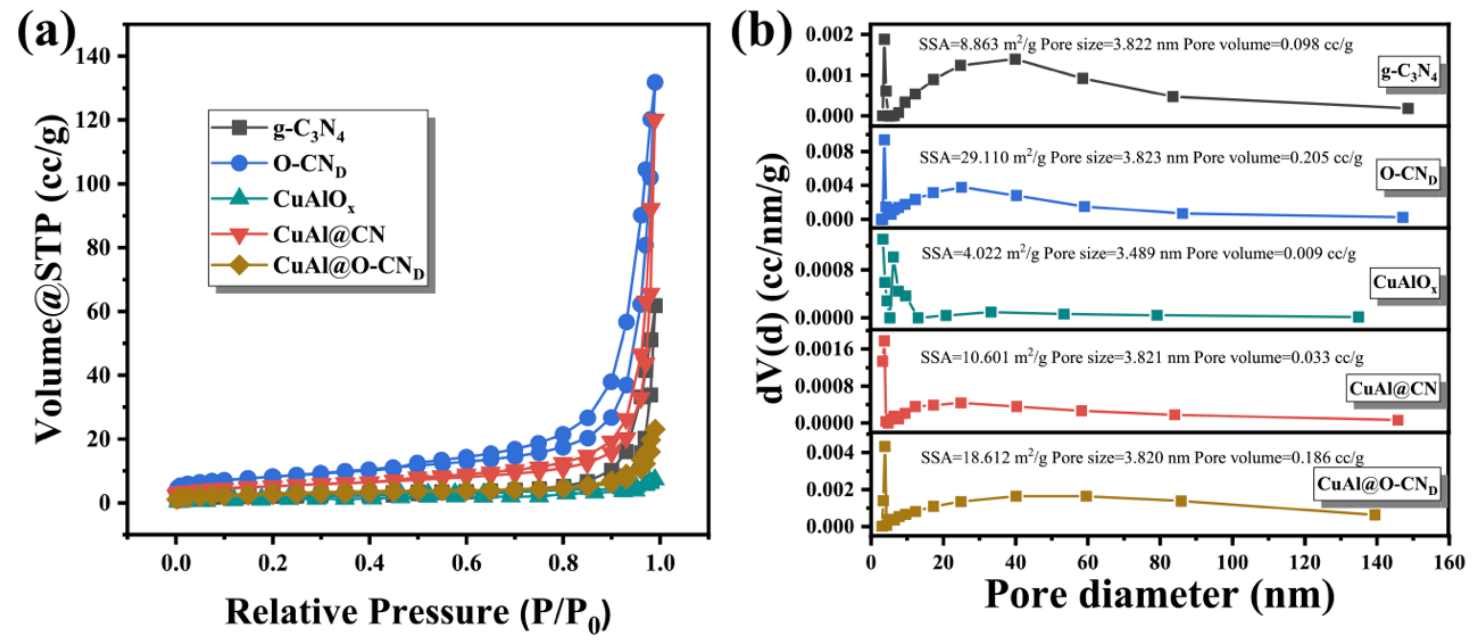

Figure S6 (a) $\mathrm{N}_{2}$ adsorption-desorption isotherms and (b) pore size distribution of $\mathrm{g}$ $\mathrm{C}_{3} \mathrm{~N}_{4}, \mathrm{O}-\mathrm{CN}_{\mathrm{D}}, \mathrm{CuAl}_{\mathrm{x}} \mathrm{O}_{\mathrm{y}}, \mathrm{CuAl} @ \mathrm{CN}, \mathrm{CuAl} @ \mathrm{O}-\mathrm{CN}_{\mathrm{D}}$.

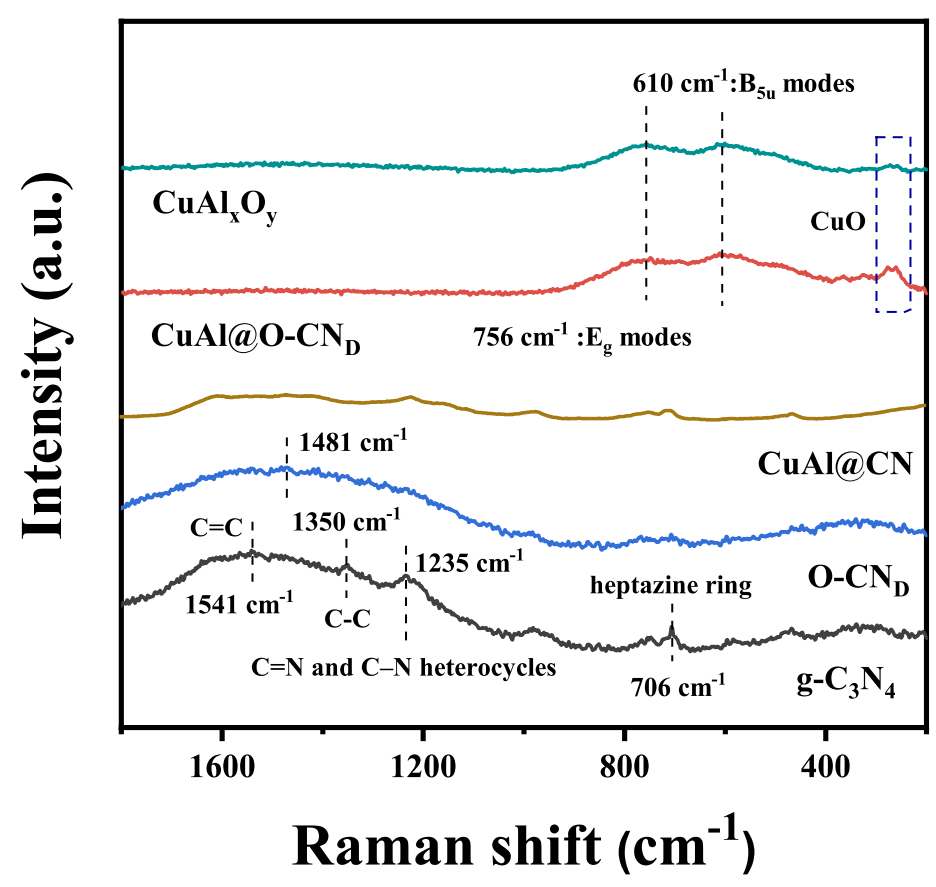

Figure S7 Raman spectra of as-prepared samples. 

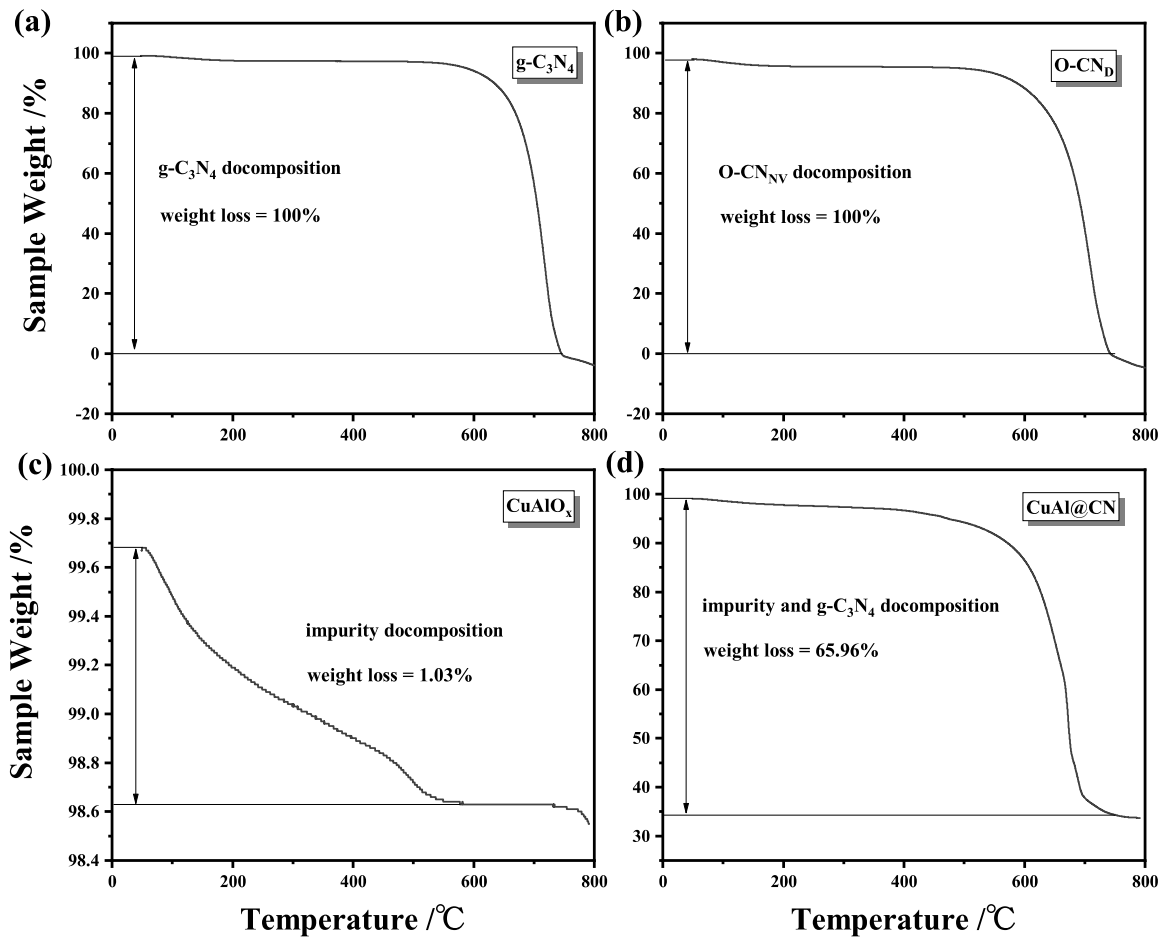

Figure S8 TGA results of (a) $\mathrm{g}-\mathrm{C}_{3} \mathrm{~N}_{4}$, (b) $\mathrm{O}-\mathrm{CN}_{\mathrm{D}}$, (c) $\mathrm{CuAlO}_{\mathrm{x}}$ and (d) $\mathrm{CuAl} @ \mathrm{CN}$. 


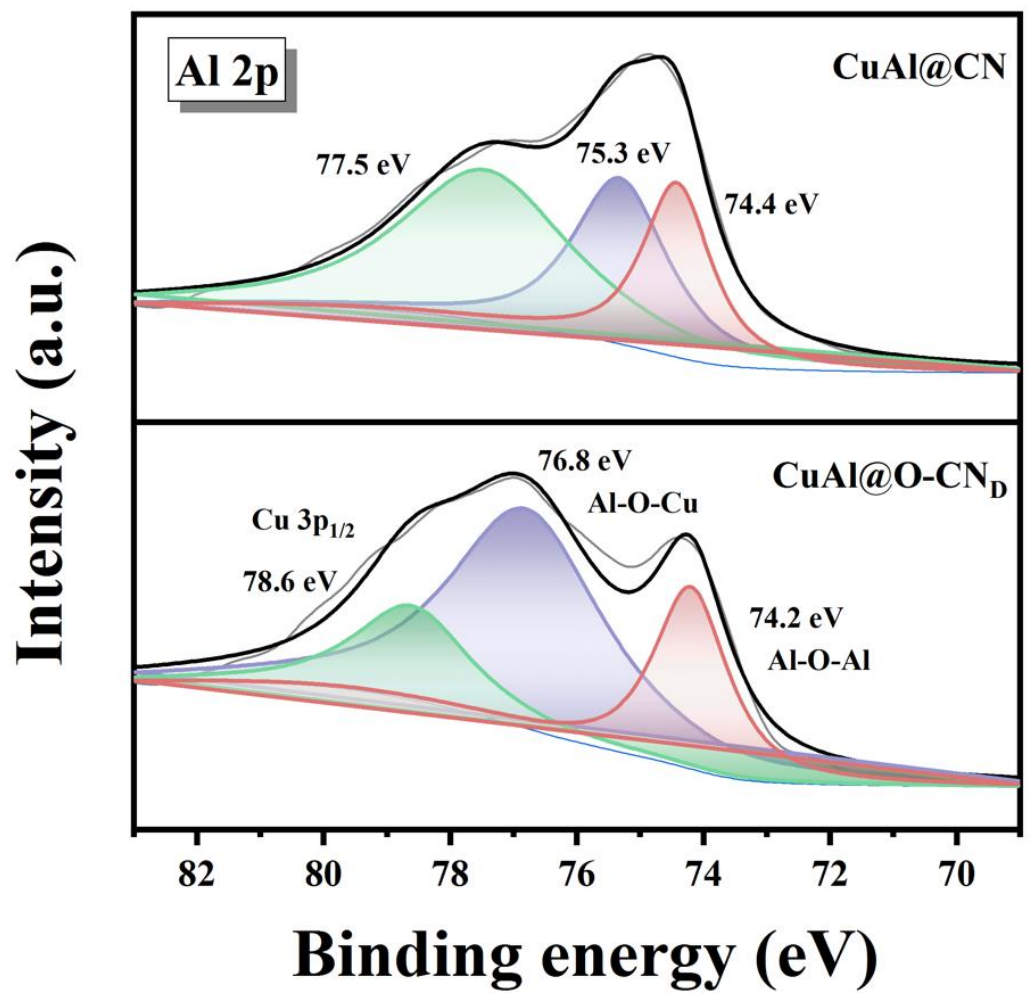

Figure S9 XPS spectra of $\mathrm{Al} 2 \mathrm{p}$ in $\mathrm{CuAl} @ \mathrm{CN}$ and $\mathrm{CuAl} @ \mathrm{O}-\mathrm{CN}_{\mathrm{D}}$. 

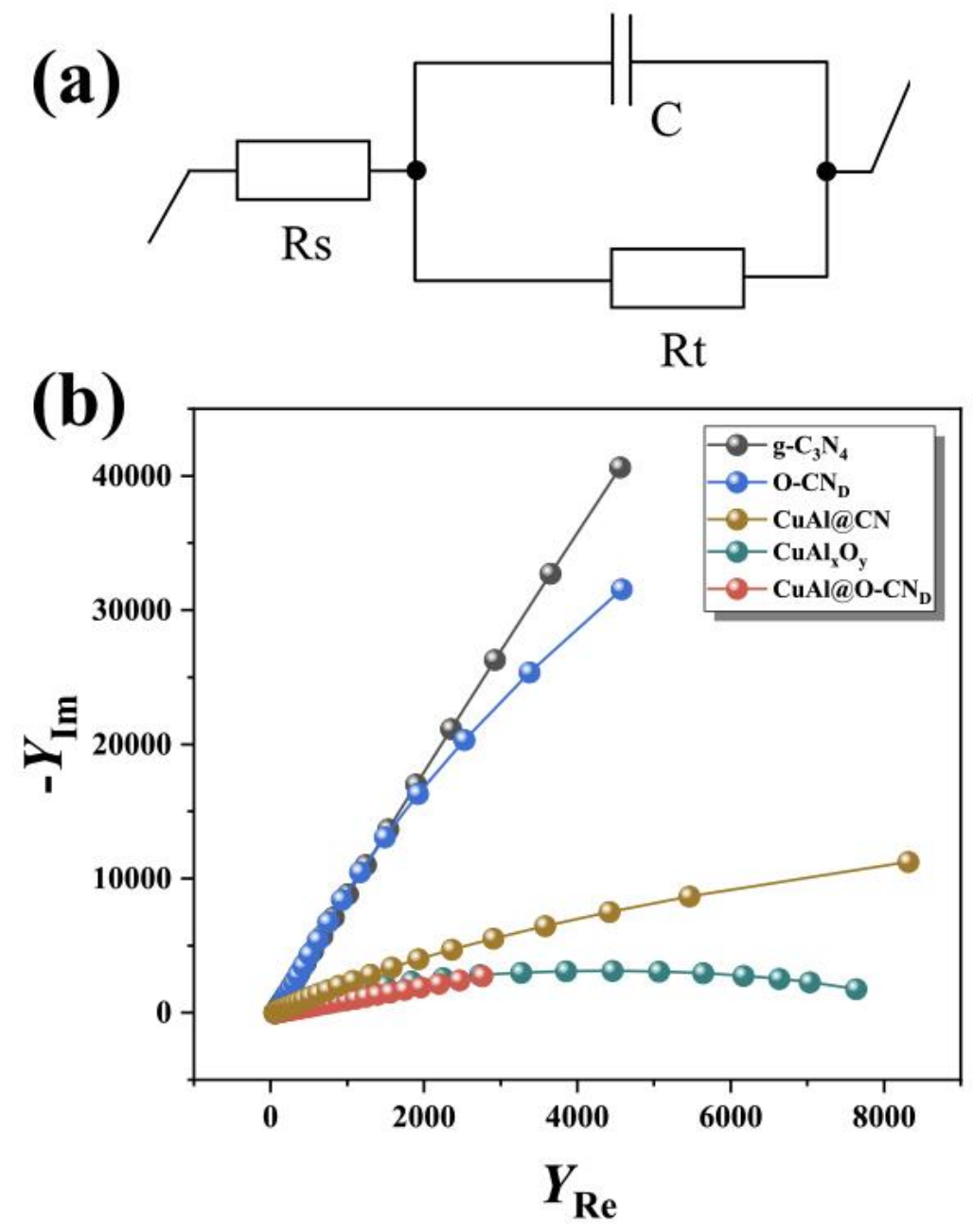

Figure S10 (a) Equivalent electric circuit (EEC). Rs, the solution resistance, C, double layer capacitance, Rt, the charge transfer resistance. (b) Fitted admittance Nyquist plots for different catalyst using the EEC. 

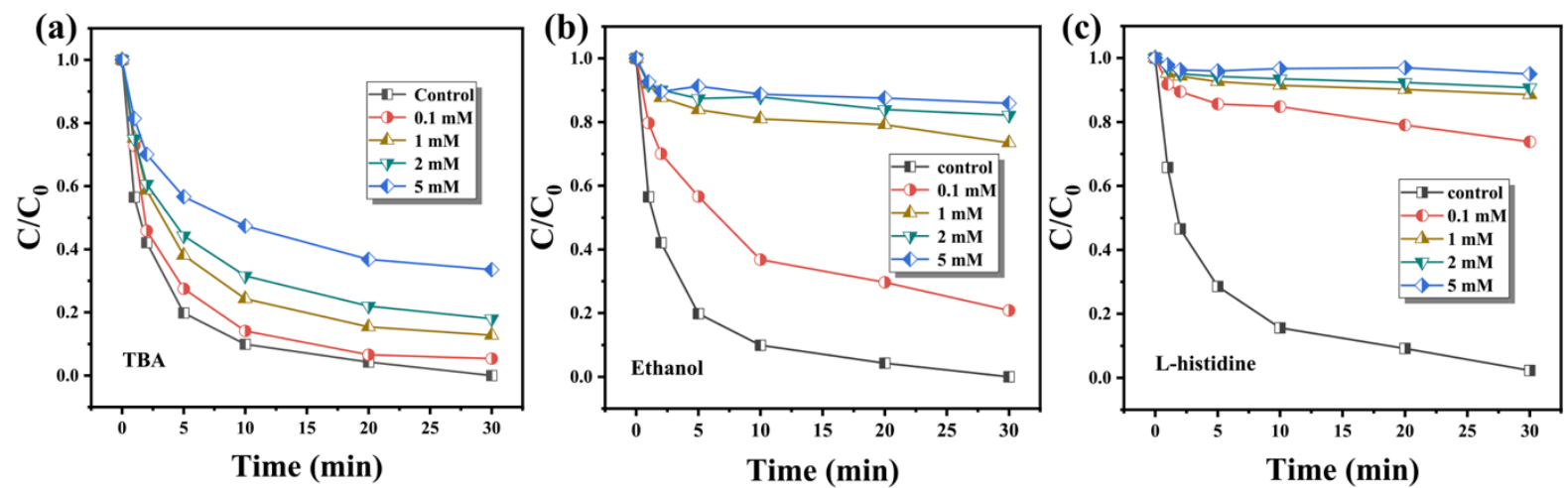

Figure S11 Quenching tests in (a) TBA, (b) Ethanol and (c) L-histidine solutions of various concentrations. Reaction conditions: $[\mathrm{TAP}]=5 \mathrm{mg} \cdot \mathrm{L}^{\square 1},[\mathrm{PMS}]=0.5 \mathrm{mM}$, catalyst $=0.5$ $\mathrm{g} \cdot \mathrm{L}^{\square 1},[\mathrm{TBA}]=0-5 \mathrm{mM},[$ Ethanol $]=0-5 \mathrm{mM},[$ L-histidine $]=0-5 \mathrm{mM}$.

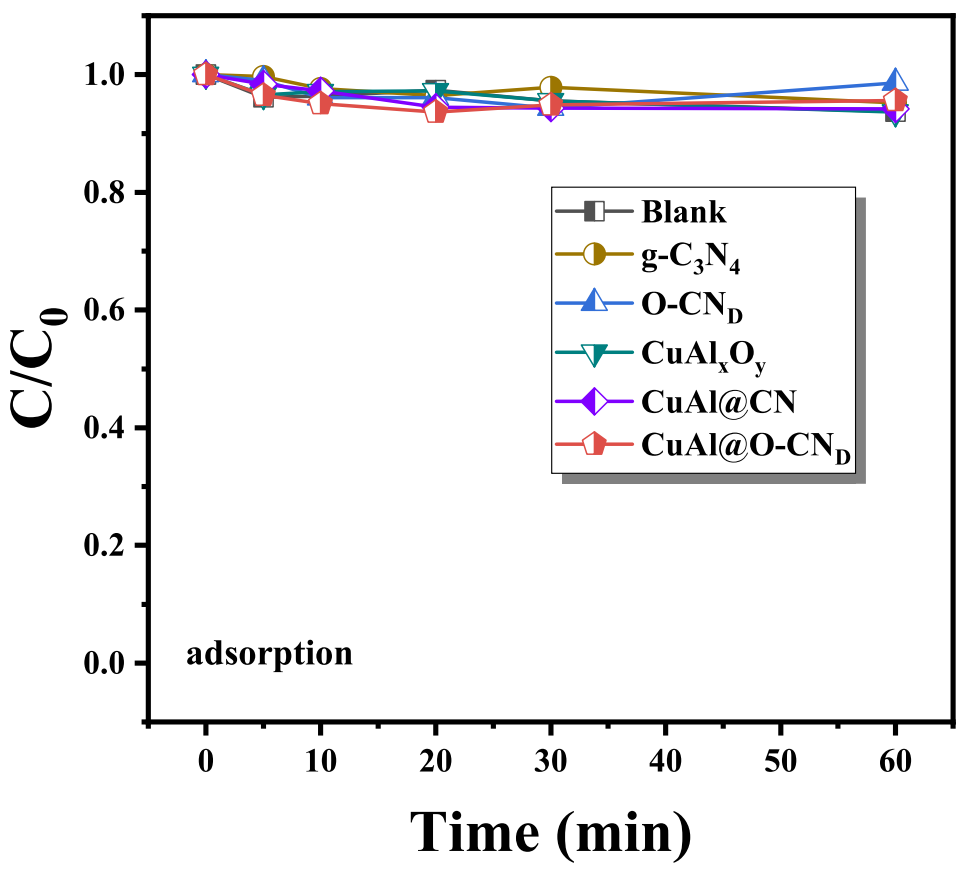

Figure S12 The adsorption experiments for different as-prepared samples. 

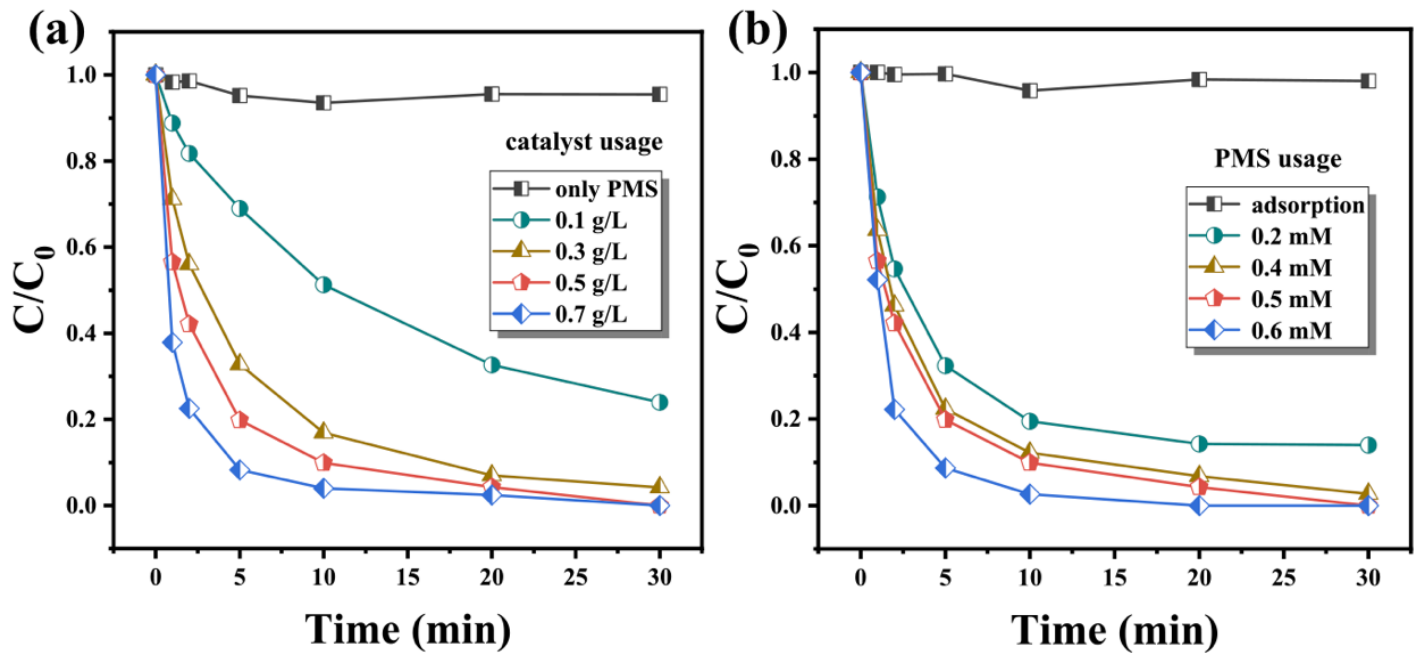

Figure S13 Effects of (a) catalyst usage, [catalyst] $=0.1-0.7 \mathrm{~g} \cdot \mathrm{L}^{\square 1}$ and (b) PMS concentration, $[\mathrm{PMS}]=0-0.6 \mathrm{mM}$ on TAP degradation.

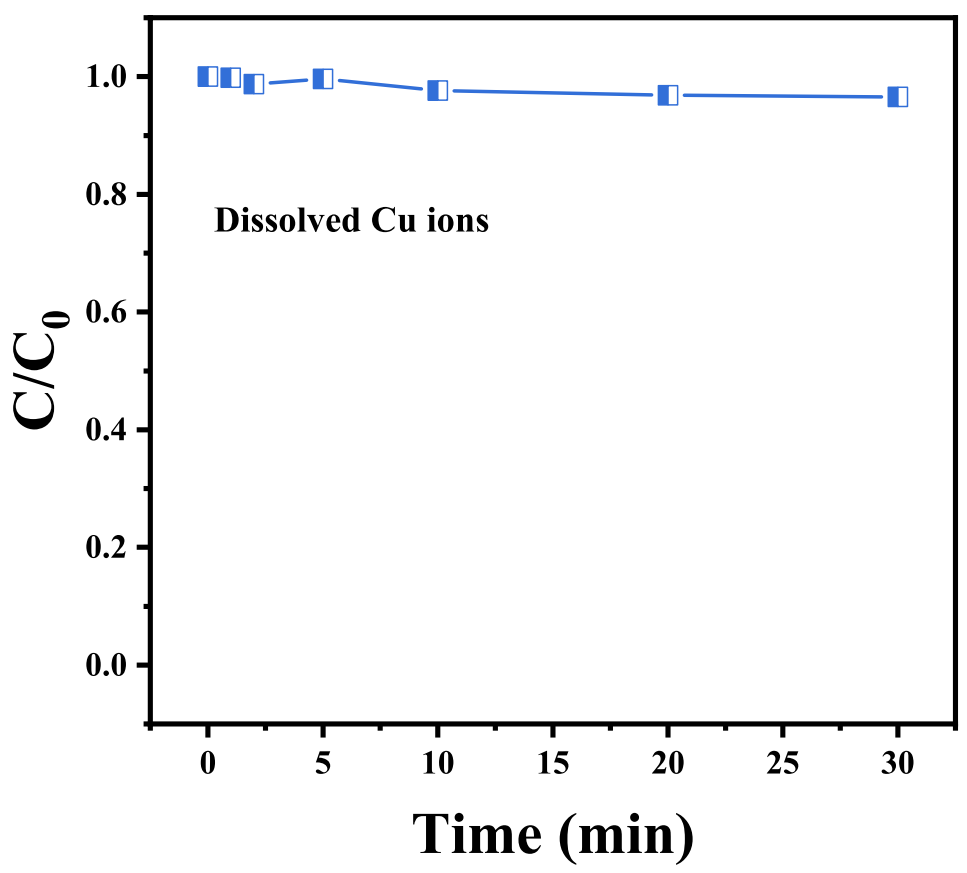

Figure S14 TAP degradation in the dissolved $\mathrm{Cu}$ ions solution. Conditions: [TAP] $=5$ $\mathrm{mg} \cdot \mathrm{L}^{\square 1}$, [catalyst $]=0.5 \mathrm{~g} \cdot \mathrm{L}^{\square 1},[\mathrm{PMS}]=0.5 \mathrm{mM}$. 